\section{The Story of Academic Ranking of World Universities}

\section{Nian Cal LiU}

Nian Cai Liu is professor and Dean of the Graduate School of Education, Shanghai Jiao Tong University, Shanghai, China. E-mail: ncliu@sjtu.edu.cn.

$\mathrm{B}$ uilding world-class universities has been the dream of generations of Chinese. At the rooth anniversary of Peking University in May 1998, the then president of China declared that the country should have several world-class universitiesresulting in the 985 Project, which is especially for building world-class universities in China.

In I998, Shanghai Jiao Tong University was selected by the Chinese government to be among the first group of nine universities in the 985 Project. At that time, many top Chinese universities drew up their strategic goals as world-class universities, and most of them set up a timetable. Shanghai Jiao Tong University was no exception. As a professor and vice-dean of the School of Chemistry and Chemical Engineering of the university, I became involved in the strategic planning process of building Shanghai Jiao Tong University into a world-class university.

During the process, I asked myself many questions. What is the definition of a world-class university? How many worldclass universities should there be globally? What are the positions of top Chinese universities in the world higher education system? How can top Chinese universities reduce their gap with world-class universities? In order to answer these questions, I started to benchmark top Chinese universities with world-class universities and eventually to rank the world universities.

\section{The Global Position of Chinese Universities}

From I999 to 200I, with Dr. Ying Cheng and two other colleagues, I worked on the project of benchmarking top Chinese universities with four groups of US universities, from the very top to ordinary research universities. The main conclusions include that top Chinese universities were estimated to be in the position of 200 to 300 in the world. The results of these comparisons and analyses were used in the strategic planning process of Shanghai Jiao Tong University. Eventually, a consultation report was written and provided to the Ministry of Education of China.

The publication of the report resulted in numerous positive comments, many of which involved the possibility of making a real ranking of world universities. During the time, many foreign friends, who visited us for other purposes, learned about our study and encouraged us to do world rankings. They reminded us that not only in China but also universities, governments, and other stakeholders in the rest of the world are interested in the ranking of world universities. Therefore, I decided to undertake this project, and with three colleagues spent another two years until the Academic Ranking of World Universities was completed in early 2003.

In June 2003, the ranking was published on our Web site (http://www.arwu.org). Although about I,200 institutions from all over the world have actually been ranked, only the lists of the top 500 institutions have been published on the Web. Considering the significance of differences in the total scale, the ranking results include groups of 50 institutions in the range of 100 to 200 and groups of Ioo institutions in the range of 200 to 500 .

\section{Ranking by Broad Subject Fields}

Ever since its publication, the ranking has attracted attention from all over the world. Numerous requests have been received, asking us to provide a ranking of world universities by broad subject fields or by schools and colleges. We have tried to respond to these requests and the results were published on our Web site in February 2007. The five broad subject fields include the natural sciences and mathematics, engineering/technology and computer sciences, life and agriculture sciences, clinical medicine and pharmacy, and the social sciences.

Although about 1,200 institutions from all over the world have actually been ranked, only the lists of the top 500 institutions have been published on the Web.

Arts and humanities were not ranked because of the technical difficulties in finding internationally comparable indicators with reliable data. Psychology and other cross-disciplinary fields were not included in the ranking because of their interdisciplinary characteristics. Two new indicators were introduced: first, the percentage of articles published in the top 20 percent journals of each broad subject field and, second, the research expenditures (for engineering ranking). The list of top Ioo universities in each broad subject field was published.

\section{Ongoing Efforts to Diversify the Ranking}

The Academic Ranking of World Universities sought to rank research universities in the world by their academic or research performance based on internationally comparable third-party data that everyone could check. The project was carried out for our academic interests, with potential impact on the strategic planning of Chinese universities.

Methodological problems involve the balance of research with teaching and service in ranking indicators and weightsinclusion of non-English publications, the selection of awards, and the experience of award winners. Technical problems exist in the definition and name given to institutions, data searching 
and cleanup of databases, and attribution of publications to institutions and broad subject fields. We have been working hard to study all the above-mentioned problems and to improve our ranking.

In addition to the broad subject field ranking, we are surveying the possibilities of providing more diversified ranking lists, particularly rankings based on different types of universities with different functions, disciplinary characteristics, history, size, and budget, as well as other topics. Furthermore, we have been doing theoretical research on ranking in general, seeking to contribute to the understanding of ranking. We have also been actively participating in international societies related to ranking such as the International Ranking Expert GroupInternational Observatory on Academic Ranking and Excellence (http://www.ireg-observatory.org).

\section{CONCLUSION}

Any ranking is controversial, and no ranking is absolutely objective. Nevertheless, university rankings have become popular in almost all major countries in the world. Whether universities and other stakeholders agree, ranking systems clearly are here to stay. The key issue then becomes how to improve ranking systems and how to use their results properly. Ranking methodologies should always be examined carefully before looking at any ranking lists, and ranking results should be used with caution.

Author's note: For additional information about the Shanghai higher education rankings, see http://www.arwu.org.

\section{The Intricacies of Academic Remuneration}

\section{Philip G. Altbach}

Philip G. Altbach is Monan University Professor and director of the Center for International Higher Education at Boston College. E-mail: altbach@bc.edu. The research referred to in this article is from Laura E. Rumbley, Iván F. Pacheco, and Philip G. Altbach, International Comparison of Academic Salaries: An Exploratory Study (2008).

T ow can we comprehend academic salaries? Does the sum 1 paid monthly to a professor constitute his or her full remuneration? Our research on international comparisons of academic salaries found major variations among countries. Differences exist as well within countries-by rank, discipline, and other factors. In some countries, salaries are determined by an individual's age, length of employment, rank, and often by civil service rules-without much cognizance of productivi- ty or academic accomplishment. Indeed, in much of the world, academics are paid on the basis of their length of service and rank alone. In other countries, particularly in some of the newer private universities, salary structures are far from transparent.

The full-time professoriate-probably a global minority of the academic profession overall, since in many countries parttimers dominate the academic system-is divided by role, function, type of institution, and discipline. As interpreted by sociologist Burton Clark, the academic profession is divided by "small worlds, different worlds." Academics are also divided by salaries. In many countries, faculty in private universities earn more than their counterparts in public institutions. Our research shows significant variations by rank. Not surprisingly, in our study of 15 countries, senior professors earned on average significantly more than junior staff.

\section{Patterns}

Among most full-time academic staff in North America, Western Europe, much of Asia, and Australia, the salary paid by the university is the bulk of the total income earned. Relatively little extra income is earned through consulting, part-time teaching, or other sources. The salary, particularly if there are two income earners in the family, provides for an adequate if not lavish middle-class lifestyle commensurate with national standards. As our research shows, while academic salaries vary considerably, in the regions mentioned here, fulltime academics can survive on their university incomes.

This is not the case in Latin America, most of Africa, or some of the countries of central and eastern Europe and the former Soviet Union. In these countries, full-time academic salaries generally do not provide sufficient income, and academics must earn additional money from other sources. Some hold more than one academic position, as the growing private higher education sector in many countries is staffed largely by "moonlighting" professors from the inadequately paid public universities. Others do consulting, own businesses, and a significant number do private tutoring or other activities that border on corrupt academic practices.

\section{Some Academics Are Less Equal Than Others}

In many countries, academic remuneration from the university is not equivalent to the base salary from the university. There are many reasons for this. Salaries are often nationally stipulated by government authorities or through union contracts or other arrangements. Universities may be unable to differentiate among disciplines, pay anything close to "market rates" to professors who are in high demand in the labor market, or reward highly productive scholars. Faculty members living in high-cost urban areas may earn the same as professors in lower-cost regions.

Most faculty members serve as teachers and possess few if any research expectations or accomplishments. In many parts of the world, particularly in developing countries, a large num- 